\title{
Disruption and Potentiation of Latent Inhibition by Risperidone: The Latent Inhibition Model of Atypical Antipsychotic Action
}

\author{
Ina Weiner*,', Daniela Schiller' and Inna Gaisler-Salomon' \\ 'Department of Psychology, Tel Aviv University, Tel Aviv, Israel
}

\begin{abstract}
Latent inhibition (LI), that is, retarded conditioning to a stimulus following its nonreinforced pre-exposure, is impaired in some subsets of schizophrenia patients and in amphetamine-treated rats. Potentiation of LI by antipsychotic drugs (APDs) given in conditioning, under conditions that do not lead to $\mathrm{LI}$ in controls, is a well-established index of antipsychotic activity. Recently, we have shown that the atypical APD, clozapine, in addition disrupts LI if administered in pre-exposure, under conditions that lead to LI in controls. This study demonstrates the same behavioral profile for the atypical APD risperidone. LI was measured in a thirst-motivated conditioned emotional response procedure by comparing suppression of drinking in response to a tone previously paired with a foot shock in rats that received nonreinforced exposure to the tone prior to conditioning (pre-exposed (PE)) and rats for whom the tone was novel (non-pre-exposed (NPE)). We show that under conditions that did not yield $\mathrm{LI}$ in vehicle controls (40 pre-exposures and five conditioning trials), risperidone $(0.25,0.5$, and $1.2 \mathrm{mg} / \mathrm{kg}$ ) led to $\mathrm{LI}$ when administered in conditioning. Under conditions that led to LI in vehicle controls ( 40 pre-exposures and two conditioning trials), risperidone $(0.25,0.5$, and $2.5 \mathrm{mg} / \mathrm{kg}$ ) abolished $\mathrm{LI}$ when administered in pre-exposure; the latter effect was not evident with haloperidol. In addition, the effects of risperidone administered in both the pre-exposure and conditioning stages were dose-dependent so that the pre-exposure-based action was manifested at lower but not at higher doses. It is concluded that atypical APDs exert in the LI model a dual pattern of effects, which enables detection of their 'typical' action (conditioning-based LI potentiation) as well as a dissociation from typical APDs by their 'atypical' action (pre-exposure-based LI disruption). It is suggested that the former and latter effects are subserved by D2 and 5HT2A antagonism, respectively.

Neuropsychopharmacology (2003) 28, 499-509. doi:I0.1038/sj.npp. 1300069
\end{abstract}

Keywords: latent inhibition; risperidone; haloperidol; atypical antipsychotic drugs; rat; schizophrenia

\section{INTRODUCTION}

Antipsychotic drugs (APDs) are currently divided into two groups: typical and atypical. There are several criteria for this distinction, extensively reviewed elsewhere (Arnt and Skarsfeldt, 1998; Brunello et al, 1995; Kinon and Lieberman, 1996). The most accepted criteria of atypicality are superior therapeutic efficacy, reduced capacity to cause extrapyramidal side effects (EPS), and reduced capacity to induce catalepsy in rodents. In addition, although atypical APDs are characterized by a broad receptor profile, their mixed DA2-5HT2 receptor antagonism has been the feature most often suggested to account for their greater antipsychotic efficacy in general, and their efficacy in improving negative symptoms in particular (Arnt and Skarsfeldt, 1998; Ichikawa and Meltzer, 1999, 2000; Leysen et al, 1993; Meltzer et al, 1989; Meltzer and Nash, 1991; Schotte et al, 1996).

\footnotetext{
*Correspondence: Dr I Weiner, Department of Psychology, Tel Aviv University, Tel Aviv 69978, Israel, E-mail: weiner@post.tau.ac.il

Received II September 2002; revised 29 August 2002; accepted 12 September 2002

Online publication: 23 September 2002 at http://www.acnp.org/ citations/Npp092302388
}

Animal models are widely used for screening and development of APDs, as well as for elucidating their mechanism of action. In addition to classical models, for example, inhibition of amphetamine/apomorphine-induced hyperactivity, newer models have been developed, which are claimed to model processes impaired in schizophrenia patients (for a review, see Arnt and Skarsfeldt, 1998). One such model that has face, construct, and predictive validity is that of latent inhibition (LI), a phenomenon whereby a repeated nonreinforced pre-exposure to a stimulus attenuates its subsequent capacity to become associated with reinforcement. LI is disrupted in rats and normal humans treated with the psychotomimetic, dopamine releasing drug amphetamine (eg Gray et al, 1992b; Killcross et al, 1994a; Thornton et al, 1996; Weiner et al, 1984, 1988, 1996b), in high schizotypal humans (eg Baruch et al, 1988b; Braunstein-Bercovitz and Lubow, 1998; De la Casa et al, 1993; Della Casa et al, 1999), and in some subsets of schizophrenia patients (eg Baruch et al, 1988a; Gray et al, 1992a, 1995; Rascle et al, 2001; Vaitl and Lipp, 1997); consequently, disrupted LI in the rat is considered to model the impaired capacity to ignore irrelevant stimuli in schizophrenia. The validity of the model is further strengthened by findings 
that the neural substrates of LI in the rat include the hippocampal formation and the nucleus accumbens, consistent with the temporal lobe and mesolimbic pathology implicated in schizophrenia (for reviews, see Moser et al, 2000; Weiner, 1990, 2000 in press; Weiner and Feldon, 1997; Weiner et al, 2000).

APDs produce two effects in the LI model: they prevent drug or lesion-induced disruption of LI (eg Coutureau et al, 2000; Gosselin et al, 1996; Warburton et al, 1994; Weiner et $a l, 1996$; Yee et al, 1995), and potentiate LI in normal rats under conditions that do not yield LI in controls, namely, low number of pre-exposures or high number of conditioning trials (eg Christison et al, 1988; Dunn et al, 1993; Feldon and Weiner, 1991; Killcross et al, 1994b; Moran et al, 1996; Shadach et al, 1999; Trimble et al, 1997; Weiner and Feldon, 1987; Weiner et al, 1996b, 1997). The latter effect is obtained also in normal humans (Williams et al, 1996, 1997). The site at which APDs act to potentiate LI in the rat is the conditioning stage, and it has been attributed to D2 receptor blockade (Peters and Joseph, 1993; Shadach et al, 1999; Weiner et al, 1996b, 1997). Potentiation of LI is a wellestablished behavioral index of antipsychotic activity, which is obtained with a variety of typical and atypical APDs differing in their in vivo and in vitro pharmacology and is selective and specific for this class of drugs, thus fulfilling the criteria for predictive validity (for a review, see Moser $e t$ $a l$, 2000; Weiner et al, 2000). Moreover, LI potentiation has a unique advantage of not requiring propsychotic drug administration for its manifestation. However, this index has a serious limitation in that it does not allow the discrimination between typical and atypical APDs. Given that the major challenge for the pharmacotherapy of schizophrenia is the development of atypical APDs, a valid animal model of APD action must enable the identification of such drugs.

Recently, we have shown that this can be attained in the LI model by using two parametric versions of the LI procedure (Shadach et al, 2000). As shown previously, with parameters that did not produce LI in controls, both the typical APD haloperidol and the atypical APD clozapine had no effect when administered in pre-exposure and potentiated LI when administered in conditioning. The novel aspect consisted of the demonstration that with parameters that led to LI in controls, clozapine but not haloperidol disrupted LI when administered in preexposure. These results provide the first demonstration suggesting that typical and atypical APDs exert distinct patterns of action in the LI model, which enable the detection of their common 'typical' action as well as their differentiation.

With regard to the possible mechanism underlying the pre-exposure-based LI disruption by clozapine, we suggested that it may be because of its 5HT2A receptor antagonism, and supported this by showing that the same effect was exerted by the 5HT2A antagonist ritanserin. We further suggested that: (1) the 5HT2A and D2 antagonistic actions of atypical APDs should compete for expression when these drugs are administered in both pre-exposure and conditioning; and (2) since the relative potencies of the two actions are dose-dependent (Ichikawa and Meltzer, 1999, 2000; Schotte et al, 1996), their manifestation in LI should also be dose-dependent.
The present experiments sought to further characterize the LI model of atypical APD action using risperidone. Risperidone is considered to share clozapine's atypical profile both clinically and pharmacologically. In the clinic, it was reported to have low EPS liability and beneficial effects on the negative symptoms of schizophrenia; pharmacologically, it combines a potent 5HT2 receptor antagonism with a milder, but still potent, D2 antagonism (eg Arnt and Skarsfeldt, 1998; Ichikawa and Meltzer, 1999, 2000; Leysen et al, 1993; Schotte et al, 1996). We expected that risperidone, similarly to clozapine, will potentiate LI via effects on conditioning under conditions that do not produce LI in controls, and disrupt LI via effects on preexposure under conditions that produce LI in controls. In addition, since the difference between the occupancy of $5 \mathrm{HT} 2 \mathrm{~A}$ and D2 receptors produced by risperidone becomes smaller as the dose is increased (Ichikawa and Meltzer, 1999, 2000; Schotte et al, 1996), we expected that when administered in both stages, its 'serotonergic' (LI disrupting) action will be manifested at lower but not at higher doses.

LI was measured in a thirst-motivated conditioned emotional response procedure by comparing the suppression of drinking to a tone previously paired with a foot shock in rats that received nonreinforced exposure to the tone prior to conditioning (pre-exposed (PE)) and in rats for whom the tone was novel (non-pre-exposed (NPE)). Experiments 1-3 sought to replicate with risperidone the finding of pre-exposure-based LI disruption observed with clozapine. For this purpose, we used pre-exposure and conditioning parameters that produce LI in controls, namely, 40 pre-exposures and two conditioning trials, and tested the effects of $0.25,0.5$, and $2.5 \mathrm{mg} / \mathrm{kg}$ risperidone, respectively. These doses were chosen on the basis of receptor occupancy data (Leysen et al, 1993; Schotte et al, $1993,1996)$ so that they produce blockade of both D2 and 5HT2A receptors but with different ratios for 5HT2A vs D2 receptor occupancy. For comparison to a typical APD, experiment 4 tested haloperidol $(0.2 \mathrm{mg} / \mathrm{kg} ; 0.1 \mathrm{mg} / \mathrm{kg}$ was used in Shadach et al, 2000) under the same conditions. Experiments 5-8 tested the effects of risperidone under conditions that do not yield LI in control rats, that is, 40 pre-exposures and five conditioning trials, in order to assess its ability to produce the 'classical' APD effect of LI potentiation. Since the $2.5 \mathrm{mg} / \mathrm{kg}$ dose reduced suppression in both the PE and the NPE groups, we also tested a lower dose of $1.2 \mathrm{mg} / \mathrm{kg}$. We present here the results of $0.25,0.5$, 1.2 , and $2.5 \mathrm{mg} / \mathrm{kg}$ doses in experiments $5-8$, respectively, although chronologically experiment 7 was run after experiment 8 . In all the experiments, the drugs were administered in either the pre-exposure stage, the conditioning stage, or in both.

\section{MATERIALS AND METHODS}

\section{Subjects}

Male Wistar rats (Tel Aviv University, Israel), approximately 4 months old and weighing $250-480 \mathrm{~g}$, were housed four to a cage under reversed cycle lighting (lights on: 19:00-07:00) with ad lib food and water except for the duration of the LI experiments (see below). All experimental 
protocols were carried out according to the guidelines of the Institutional Animal Care and Use Committee of Tel Aviv University.

\section{Apparatus and Procedure}

LI was tested in Campden Instruments rodent test chambers (Model 410) with a retractable bottle. When the bottle was not present, the hole was covered by a metal lid. Licks were detected by a Campden Instruments drinkometer (Model 453). The PE to-be-conditioned stimulus was a $10 \mathrm{~s}, 80 \mathrm{~dB}$, $2.8 \mathrm{kHz}$ tone produced by a Sonalert module (Model SC 628). Shock was supplied through the floor by a Campden Instruments shock generator (Model 521/C) and shock scrambler (Model 521/S) set at $0.4 \mathrm{~mA}$ and $1 \mathrm{~s}$ duration. Equipment programming and data recording were computer controlled.

Prior to the beginning of each LI experiment, rats were handled for about 2 min daily for 5 days. A $23 \mathrm{~h}$ water restriction schedule was initiated simultaneously with handling and continued throughout the experiment. On the next 5 days, rats were trained to drink in the experimental chamber for $15 \mathrm{~min} /$ day. Water in the test apparatus was given in addition to the daily ration of $1 \mathrm{~h}$ given in the home cages. The LI procedure was conducted on days 11-14 and consisted of four stages given $24 \mathrm{~h}$ apart. Pre-exposure: With the bottle removed, the PE rats received 40 tone presentations with an interstimulus interval of $40 \mathrm{~s}$. The NPE rats were confined to the chamber for an identical period of time without receiving the tone. Conditioning: With the bottle removed, each rat received two (experiments 1-4) or five (experiments 5-8) tone-shock pairings given $5 \mathrm{~min}$ apart. Shock immediately followed tone termination. The first tone-shock pairing was given $5 \mathrm{~min}$ after the start of the session. After the last pairing, rats were left in the experimental chamber for an additional $5 \mathrm{~min}$. Retraining: Rats were given a 15 min drinking session as in initial training. Data of rats that failed to complete 600 licks were dropped from the analysis. Test: Each rat was placed in the chamber and allowed to drink from the bottle. When the rat completed 75 licks, the tone was presented for $5 \mathrm{~min}$. The following times were recorded: time to first lick, time to complete licks 1-50, time to complete licks 51-75 (before tone onset), and time to complete licks 76-100 (after tone onset). Times to complete licks $76-100$ were logarithmically transformed to allow parametric analysis of variance. Longer log times indicate a stronger suppression of drinking. LI is defined as significantly shorter log times to complete licks $76-100$ of the PE as compared to NPE rats.

\section{Drugs}

All drugs were administered IP in a volume of $1 \mathrm{ml} / \mathrm{kg}$ prior to the pre-exposure and/or conditioning stages. Risperidone (Janssen, Belgium), mixed with tartaric acid and diluted in saline, was administered $30 \mathrm{~min}$ prior to the appropriate sessions at doses of $0.25,0.5,1.2$, and $2.5 \mathrm{mg} / \mathrm{kg}$. Haloperidol, prepared from an ampoule containing $5 \mathrm{mg}$ haloperidol in $1 \mathrm{ml}$ solvent containing $6 \mathrm{mg}$ lactic acid (Janssen, Belgium) and diluted with saline, was administered $60 \mathrm{~min}$ prior to the behavioral sessions at a dose of $0.2 \mathrm{mg} / \mathrm{kg}$. No- drug controls received an equivalent volume of the corresponding vehicle.

\section{Experimental Design}

All the experiments included eight experimental groups in a $2 \times 2 \times 2$ design with main factors of pre-exposure (NPE, $\mathrm{PE}$ ), drug in pre-exposure (vehicle, drug (risperidone or haloperidol)), and drug in conditioning (vehicle, drug (risperidone or haloperidol)). Experiments 3 and 5-8 tested 42-48 rats. Since some statistical results in experiments 1, 2, and 4 came close to the acceptable level of significance, an additional replication was conducted for each experiment.

\section{Statistical Analysis}

Times to complete licks $51-75$ and mean log times to complete licks 76-100 were analyzed by $2 \times 2 \times 2$ ANOVA with main factors of pre-exposure $(0,40)$, drug in preexposure (vehicle, drug), and drug in conditioning (vehicle, drug). In all cases of significant interactions, post hoc twotailed $t$-tests based on the error term derived from the ANOVA were used to assess the difference between the PE and NPE groups within the relevant drug conditions.

\section{RESULTS}

Experiment 1 -Effects of $0.25 \mathrm{mg} / \mathrm{kg}$ Risperidone on LI with 40 Pre-exposures and Two Conditioning Trials

The experiment included 85 rats, run in two replications; the data of four rats were dropped from the analysis. The eight experimental groups did not differ in their times to complete licks 51-75 (before tone onset; all $p$ 's $>0.05$; overall mean A period $=8.83 \mathrm{~s}$ ). Figure $1 \mathrm{a}$ presents the mean log times to complete licks 76-100 (after tone onset) of the PE and NPE groups in the four drug conditions in pre-exposure and conditioning: vehicle-vehicle, risperidone-vehicle, vehicle-risperidone, and risperidone-risperidone. ANOVA yielded a significant main effect of preexposure $\mathrm{F}(1,73)=4.9, p<0.05$, reflecting the fact, that overall, the PE groups were less suppressed (had shorter log times) than the NPE groups, and a significant main effect of drug in conditioning $\mathrm{F}(1,73)=9.48, p<0.01$, indicating that, overall, the groups that received risperidone in conditioning were less suppressed than the groups that received vehicle in conditioning. In addition, there was a significant pre-exposure $\times$ drug in pre-exposure interaction $\mathrm{F}(1,73)=8.06, p<0.01$, indicating that the effect of preexposure differed depending on whether rats were injected with vehicle or risperidone in pre-exposure, irrespective of the drug received in conditioning. The pre-exposure $\times$ drug in pre-exposure interaction is depicted in Figure 1b, which presents the mean log times to complete licks 76-100 of the $\mathrm{PE}$ and NPE groups that received vehicle in pre-exposure (vehicle-vehicle and vehicle-risperidone) or risperidone in pre-exposure (risperidone-vehicle and risperidone-risperidone). As can be seen, shorter log times of the PE as compared to the non-PE group, that is, LI, were found in rats that received vehicle in pre-exposure. In contrast, there was no difference in suppression between the PE and NPE groups, that is, no LI, in rats that received risperidone in 

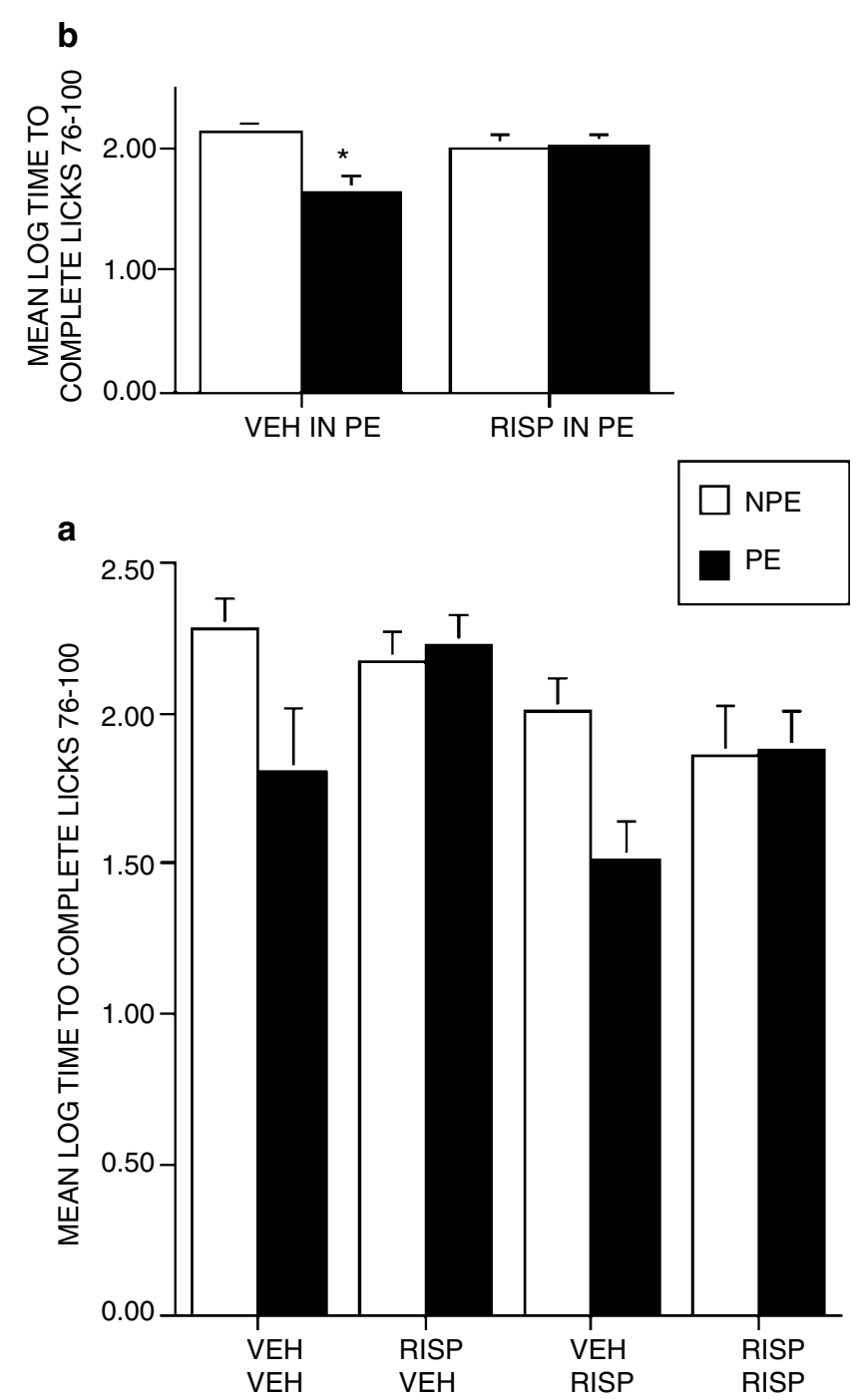

Figure I (a) Means and standard errors of the log times to complete licks 76-100 (after tone onset) of the PE and NPE groups in four drug conditions in pre-exposure and conditioning: vehicle-vehicle, risperidonevehicle, vehicle-risperidone, and risperidone-risperidone. (b) Means and standard errors of the log times to complete licks 76-100 (after tone onset) of the PE and NPE groups in two drug conditions in pre-exposure: vehicle or risperidone. Forty tone pre-exposures and two tone-shock pairings were used. A dose of $0.25 \mathrm{mg} / \mathrm{kg}$ of risperidone was administered.
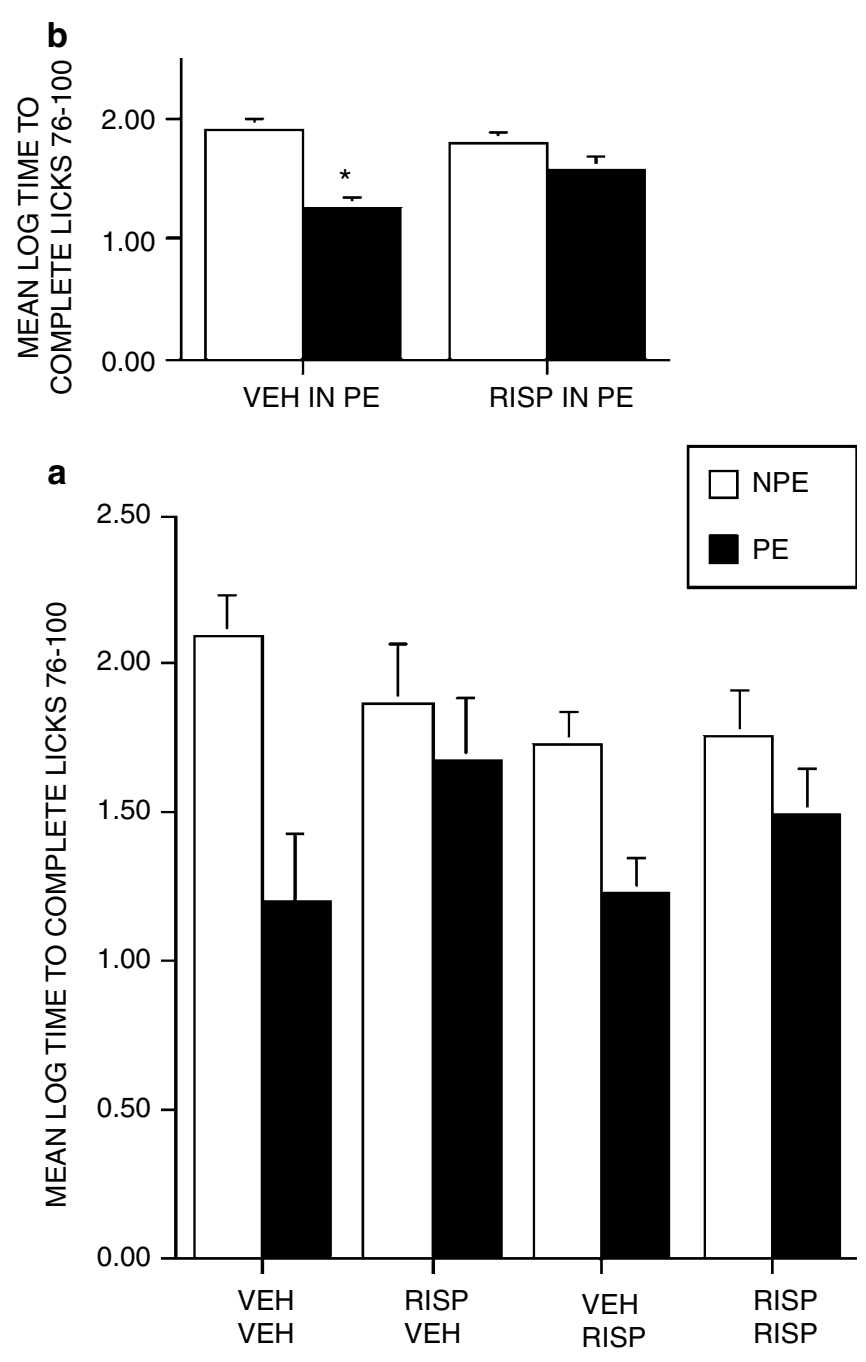

Figure 2 (a) Means and standard errors of the log times to complete licks 76-100 (after tone onset) of the PE and NPE groups in four drug conditions in pre-exposure and conditioning: vehicle-vehicle, risperidonevehicle, vehicle-risperidone, and risperidone-risperidone. (b) Means and standard errors of the log times to complete licks 76-100 (after tone onset) of the PE and NPE groups in two drug conditions in pre-exposure: vehicle or risperidone. Forty tone pre-exposures and two tone-shock pairings were used. A dose of $0.5 \mathrm{mg} / \mathrm{kg}$ of risperidone was administered.

exposure and conditioning: vehicle-vehicle, risperidonevehicle, vehicle-risperidone, and risperidone-risperidone. ANOVA yielded a significant main effect of pre-exposure $\mathrm{F}(1,79)=18.27, p<0.0001$, reflecting the fact that overall, the PE groups were less suppressed than the NPE groups, as well as a significant pre-exposure $\times$ drug in pre-exposure interaction $\mathrm{F}(1,79)=4.26, p<0.05$, indicating that the effect of pre-exposure differed depending on whether rats were injected with vehicle or risperidone in pre-exposure. The pre-exposure $\times$ drug in pre-exposure interaction is depicted in Figure 2b, which presents the mean log times to complete licks 76-100 of the PE and NPE groups that received vehicle in pre-exposure (vehicle-vehicle and vehicle-risperidone) or risperidone in pre-exposure (risperidone-vehicle and risperidone-risperidone). As can be seen, shorter log times 
of the PE as compared to the NPE group, that is, LI, were found in rats that received vehicle in pre-exposure. In contrast, there was no difference in suppression between the $\mathrm{PE}$ and NPE groups, that is, no LI, in rats that received risperidone in pre-exposure. This was confirmed by post hoc $t$-tests which revealed the existence of LI in the vehicle in pre-exposure condition $t(79)=4.3, p<0.0001$ but not in the risperidone in pre-exposure condition $t(79)=1.69$, NS.

\section{Experiment 3 -Effects of $2.5 \mathrm{mg} / \mathrm{kg}$ Risperidone On LI} with 40 Pre-Exposures and Two Conditioning Trials

The experiment included 47 rats; the data of three rats were dropped from the analysis. The eight experimental groups did not differ in their times to complete licks 51-75 (all $p$ 's $>0.05$; overall mean A period $=8.3 \mathrm{~s}$ ). Figure 3 presents the mean log times to complete licks 76-100 (after tone onset) of the PE and NPE groups in the four drug conditions in pre-exposure and conditioning: vehiclevehicle, risperidone-vehicle, vehicle-risperidone, and risperidone-risperidone. ANOVA yielded a significant main effect of pre-exposure $\mathrm{F}(1,36)=15.39, p<0.001$, reflecting the fact that, overall, the PE groups were less suppressed than the NPE groups, and a significant main effect of drug in conditioning $\mathrm{F}(1,36)=10.37, p<0.005$, indicating that, overall, the groups that received risperidone in conditioning were less suppressed than the groups that received vehicle in conditioning. In addition, there was a significant preexposure $\times$ drug in pre-exposure $\times$ drug in conditioning interaction $\mathrm{F}(1,36)=4.24 p<0.05$, indicating that the effect of pre-exposure was a function of the combination of drug administered in pre-exposure and drug administered in conditioning. As can be seen in Figure 3, LI was present in

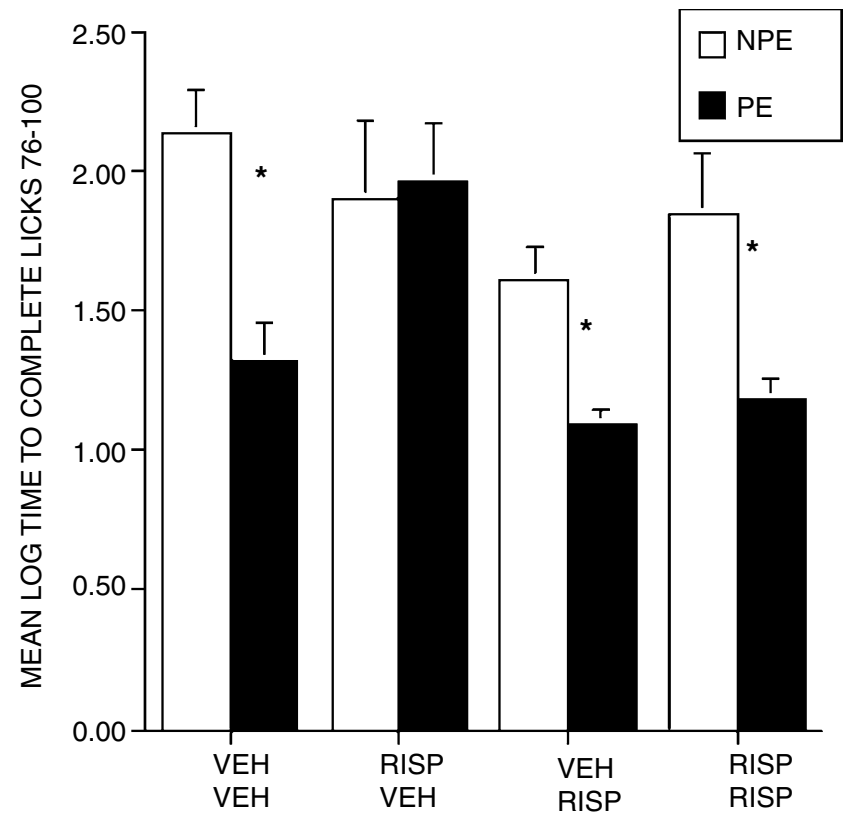

Figure 3 Means and standard errors of the log times to complete licks 76-100 (after tone onset) of the PE and NPE groups in four drug conditions in pre-exposure and conditioning: vehicle-vehicle, risperidonevehicle, vehicle-risperidone, and risperidone-risperidone. Forty tone preexposures and two tone-shock pairings were used. A dose of $2.5 \mathrm{mg} / \mathrm{kg}$ of risperidone was administered. rats that received vehicle in both the pre-exposure and the conditioning stages, as well as in rats that received risperidone in conditioning, irrespective of the drug received in pre-exposure. In contrast, there was no LI in rats that received risperidone in pre-exposure and vehicle in conditioning. Post hoc $t$-tests confirmed the existence of LI in the vehicle-vehicle $t(36)=3.17, p<0.01$, vehicle-risperidone $t(36)=2.12, p<0.05$, and risperidone-risperidone $t(36)=2.80, p<0.01$ conditions, but not in the risperidonevehicle condition $t(36)<1$, NS.

Experiment 4 - Effects of $0.2 \mathrm{mg} / \mathrm{kg}$ Haloperidol on LI with 40 Pre-Exposures and Two Conditioning Trials

The experiment included 91 rats; the data of one rat were dropped from the analysis. The eight experimental groups did not differ in their times to complete licks 51-75 (all $p$ 's $>0.05$; overall mean A period $=7.93 \mathrm{~s}$ ). Figure 4 presents the mean log times to complete licks $76-100$ of the PE and NPE groups in the four drug conditions in pre-exposure and conditioning: vehicle-vehicle, haloperidol-vehicle, vehicle-haloperidol, and haloperidol-haloperidol. ANOVA yielded only a significant main effect of pre-exposure $\mathrm{F}(1,82)=14.45, p<0.001$, reflecting the fact that, overall, $\mathrm{PE}$ rats were less suppressed than NPE rats, that is, there was LI.

\section{Experiment 5 -Effects of $0.25 \mathrm{mg} / \mathrm{kg}$ Risperidone on LI} with 40 Pre-Exposures and Five Conditioning Trials

The experiment included 41 rats; the data of three rats were dropped from the analysis. The eight experimental groups did not differ in their times to complete licks 51-75 (all

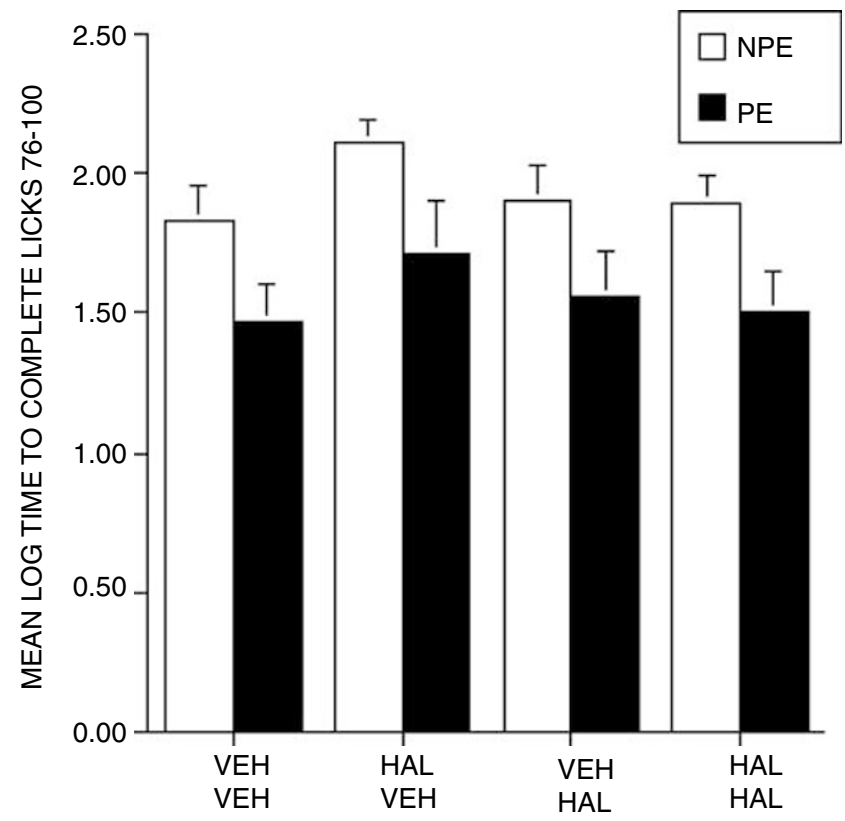

Figure 4 Means and standard errors of the log times to complete licks 76-100 (after tone onset) of the PE and NPE groups in four drug conditions in pre-exposure and conditioning: vehicle-vehicle, haloperidolvehicle, vehicle-haloperidol, haloperidol-haloperidol. Forty tone preexposures and two tone-shock pairings were used. A dose of $0.2 \mathrm{mg} / \mathrm{kg}$ of haloperidol was administered. 
p's $>0.05$; overall mean A period $=7.8 \mathrm{~s}$ ). Figure 5 presents the mean log times to complete licks 76-100 (after tone onset) of the PE and NPE groups in the four drug conditions in pre-exposure and conditioning: vehiclevehicle, risperidone-vehicle, vehicle-risperidone, and risperidone-risperidone. ANOVA yielded a significant preexposure $\times$ drug in pre-exposure $\times$ drug in conditioning interaction $F(1,30)=6.93, p<0.025$, indicating that the effect of pre-exposure was a function of the combination of drug in pre-exposure and drug in conditioning. As can be seen in Figure 5, there was no LI in rats that received vehicle in both the pre-exposure and the conditioning stages, as well as in rats that received risperidone in pre-exposure, irrespective of the drug received in conditioning (risperidone-vehicle and risperidone-risperidone conditions). In contrast, LI was present in rats that received vehicle in preexposure and risperidone in conditioning. Post hoc t-tests confirmed the existence of LI in the vehicle-risperidone condition $t(30)=2.96, p<0.01$, but not in the vehicle-vehicle $t(30)<1$, NS, risperidone-vehicle $t(30)=$ 1.11 , NS, and risperidone-risperidone $t(30)<1$, NS, conditions.

\section{Experiment 6-Effects of $0.5 \mathrm{mg} / \mathrm{kg}$ Risperidone on LI with 40 Pre-Exposures and Five Conditioning Trials}

The experiment included 47 rats; the data of three rats were dropped from the analysis. The eight experimental groups did not differ in their times to complete licks 51-75 (all $p$ 's $>0.05$; overall mean A period $=8.4 \mathrm{~s}$ ). Figure $6 \mathrm{a}$ presents the mean log times to complete licks 76-100 (after tone onset) of the PE and NPE groups in the four drug

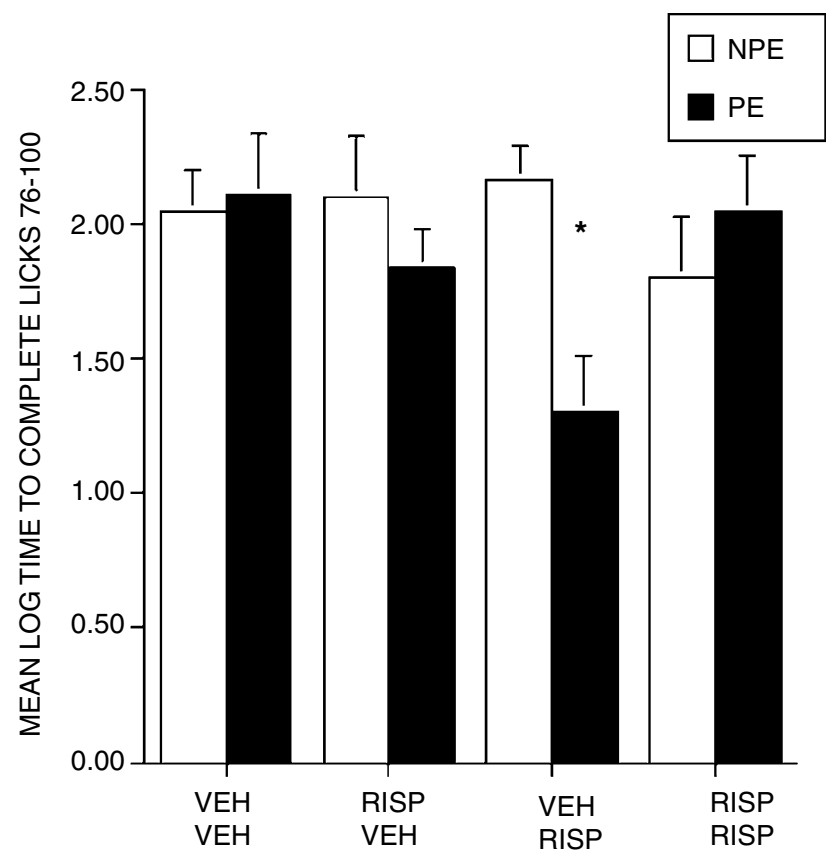

Figure 5 Means and standard errors of the log times to complete licks 76-100 (after tone onset) of the PE and NPE groups in four drug conditions in pre-exposure and conditioning: vehicle-vehicle, risperidonevehicle, vehicle-risperidone, and risperidone-risperidone. Forty tone preexposures and five tone-shock pairings were used. A dose of $0.25 \mathrm{mg} / \mathrm{kg}$ of risperidone was administered.
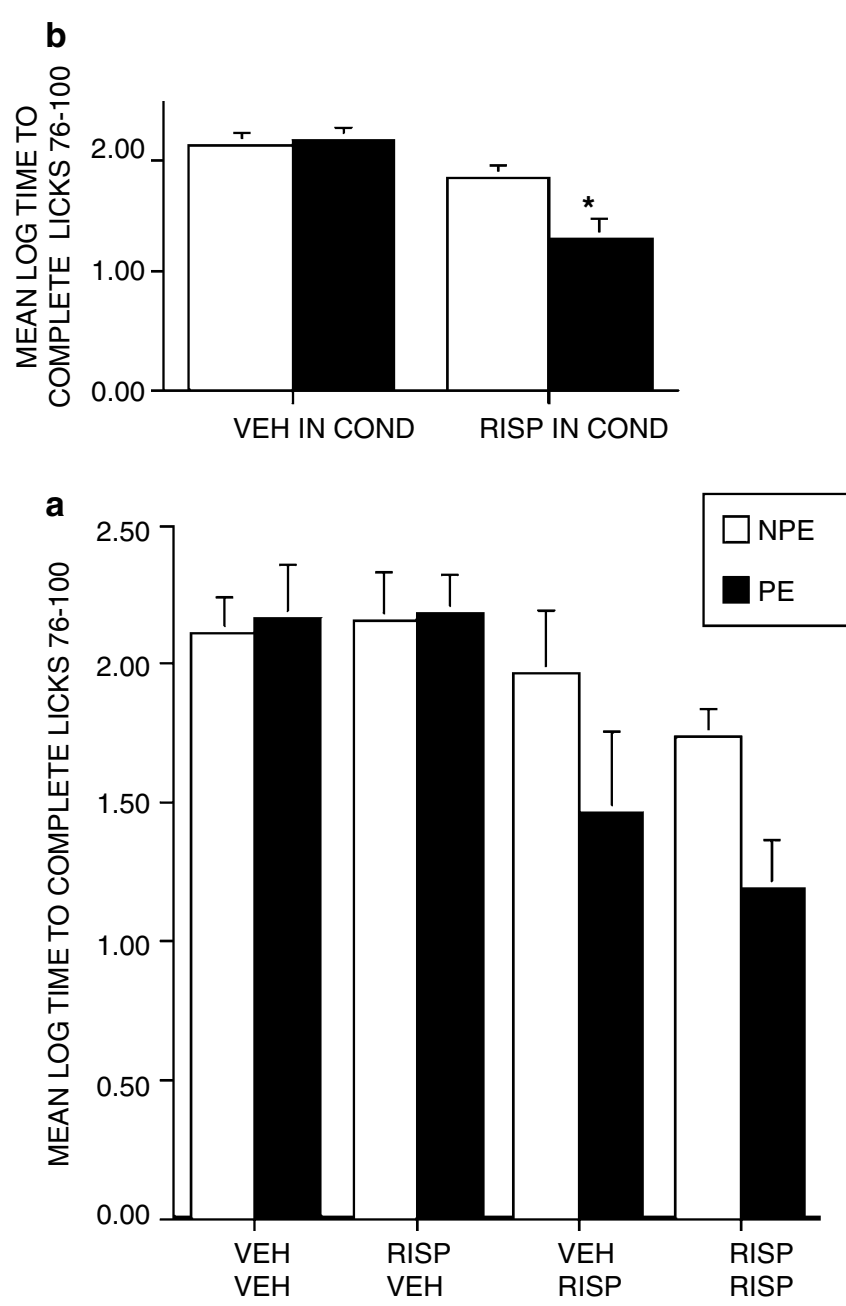

Figure 6 (a) Means and standard errors of the log times to complete licks 76-100 (after tone onset) of the PE and NPE groups in four drug conditions in pre-exposure and conditioning: vehicle-vehicle, risperidonevehicle, vehicle-risperidone, and risperidone-risperidone. (b) Means and standard errors of the log times to complete licks 76-100 (after tone onset) of the PE and NPE groups in two drug conditions in conditioning: vehicle or risperidone. Forty tone pre-exposures and five tone-shock pairings were used. A dose of $0.5 \mathrm{mg} / \mathrm{kg}$ of risperidone was administered.

conditions in pre-exposure and conditioning: vehiclevehicle, risperidone-vehicle, vehicle-risperidone, and risperidone-risperidone. ANOVA yielded a significant main effect of drug in conditioning $\mathrm{F}(1,36)=20.14, p<0.0001$, indicating that, overall, the groups that received risperidone in conditioning were less suppressed than the groups that received vehicle in conditioning, as well as a significant preexposure $\times$ drug in conditioning interaction $\mathrm{F}(1,36)=5.02$, $p<0.05$, indicating that the effect of pre-exposure differed depending on whether rats were given risperidone or vehicle in conditioning, irrespective of the drug condition in pre-exposure. The pre-exposure $\times$ drug in conditioning interaction is depicted in Figure 6b, which presents the mean $\log$ times to complete licks $76-100$ of the $\mathrm{PE}$ and NPE groups that received vehicle in conditioning (vehicle-vehicle and risperidone-vehicle) or risperidone in conditioning (vehicle-risperidone and risperidone-risper- 
idone). As can be seen, there was no LI in rats that received vehicle in conditioning whereas rats that received risperidone in conditioning exhibited LI. Post hoc $t$-tests confirmed the existence of LI in the groups that received risperidone in conditioning $t(36)=2.82, p<0.01$ but not in those that received vehicle in conditioning $t(36)<1$, NS.

\section{Experiment 7 - Effects of $1.2 \mathrm{mg} / \mathrm{kg}$ Risperidone on LI} with 40 Pre-Exposures and Five Conditioning Trials

The experiment included 44 rats. The eight experimental groups did not differ in their times to complete licks 51-75 (all $p$ 's $>0.5$; overall mean A period $=11.1 \mathrm{~s}$ ). Figure $7 \mathrm{a}$ presents the mean log times to complete licks 76-100 of the $\mathrm{PE}$ and NPE groups in the four drug conditions in preexposure and conditioning: vehicle-vehicle, risperidone-
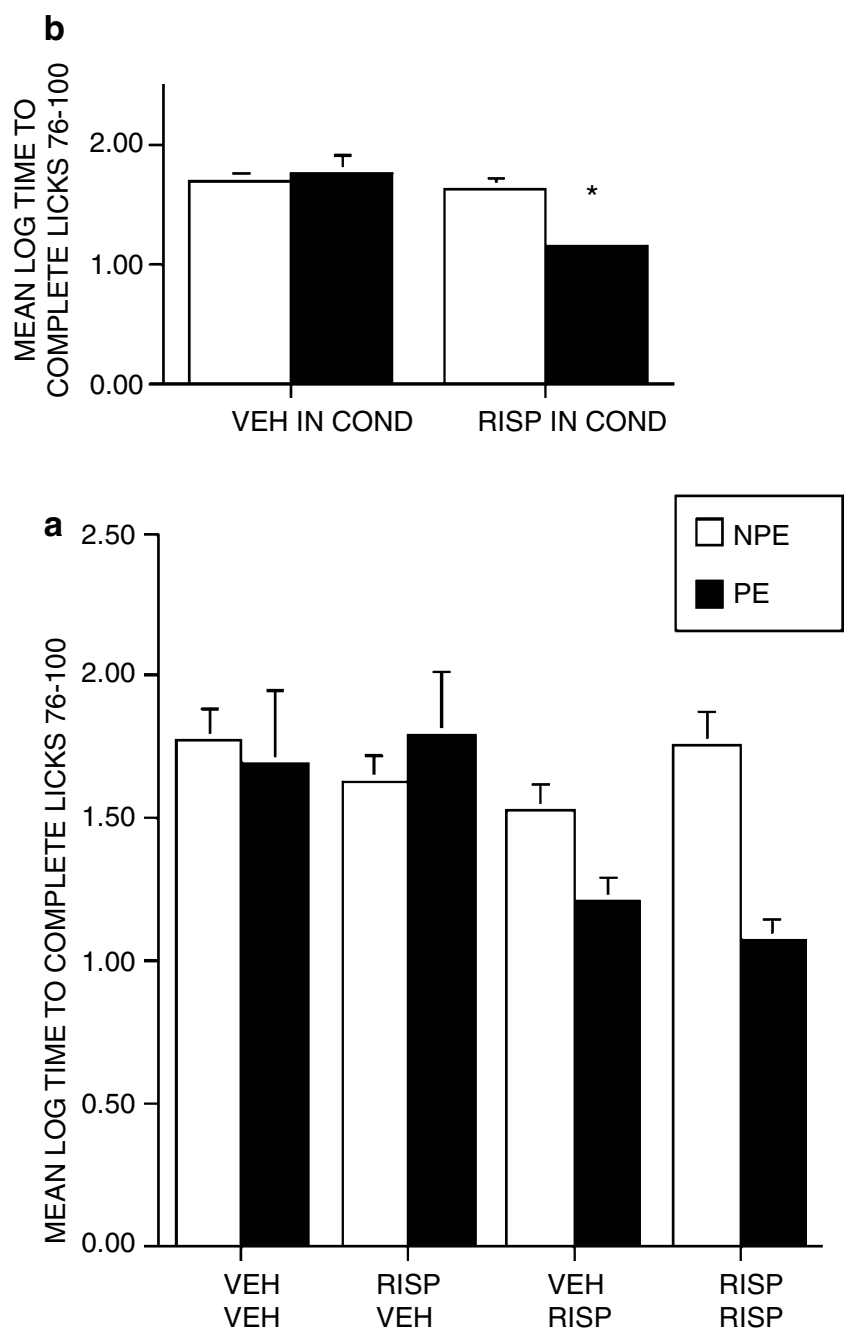

Figure 7 (a) Means and standard errors of the log times to complete licks 76-100 (after tone onset) of the PE and NPE groups in four drug conditions in pre-exposure and conditioning: vehicle-vehicle, risperidonevehicle, vehicle-risperidone, and risperidone-risperidone. (b) Means and standard errors of the log times to complete licks 76-100 (after tone onset) of the PE and NPE groups in two drug conditions in conditioning: vehicle or risperidone. Forty tone pre-exposures and five tone-shock pairings were used. A dose of $1.2 \mathrm{mg} / \mathrm{kg}$ of risperidone was administered. vehicle, vehicle-risperidone, and risperidone-risperidone. ANOVA yielded significant main effects of pre-exposure $\mathrm{F}(1,36)=5.42, \quad p<0.05$ and drug in conditioning $\mathrm{F}(1,36)=11.73, p<0.025$, as well as a significant preexposure $\times$ drug in conditioning interaction $\mathrm{F}(1,36)=7.53$, $\mathrm{p}<0.025$. The interaction is depicted in Figure $7 \mathrm{~b}$, which presents the mean log times to complete licks 76-100 of the $\mathrm{PE}$ and NPE groups that received vehicle in conditioning (vehicle-vehicle and risperidone-vehicle) or risperidone in conditioning (vehicle-risperidone and risperidone-risperidone). As can be seen, there was no LI in rats that received vehicle in conditioning, whereas rats that received risperidone in conditioning exhibited LI. Post hoc t-tests confirmed the existence of LI in the risperidone $t(36)=3.80, p<0.01$ but not in the vehicle condition $t(36)<1$, NS.

\section{Experiment 8 - Effects of $2.5 \mathrm{mg} / \mathrm{kg}$ Risperidone on LI} with 40 Pre-Exposures and Five Conditioning Trials

The experiment included 47 rats; the data of one rat were dropped from the analysis. The eight experimental groups did not differ in their times to complete licks 51-75 (all $p$ 's $>0.05$; overall mean A period $=9.8 \mathrm{~s}$ ). Figure 8 presents the mean log times to complete licks $76-100$ of the PE and NPE groups in the four drug conditions in pre-exposure and conditioning: vehicle-vehicle, risperidone-vehicle, vehicle-risperidone, and risperidone-risperidone. ANOVA yielded a significant main effect of drug in conditioning $\mathrm{F}(1,38)=29.72, p<0.0001$, but no other significant outcomes. As can be seen, there was no LI in any of the conditions.

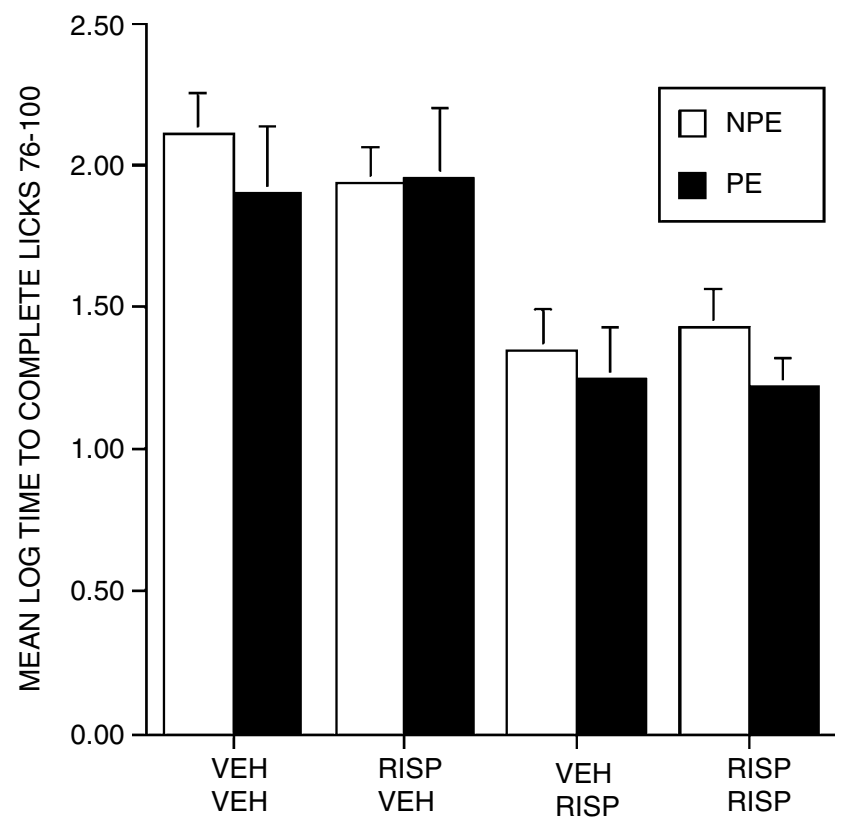

Figure 8 Means and standard errors of the log times to complete licks 76-100 (after tone onset) of the PE and NPE groups in four drug conditions in pre-exposure and conditioning: vehicle-vehicle, risperidonevehicle, vehicle-risperidone, and risperidone-risperidone. Forty tone preexposures and five tone-shock pairings were used. A dose of $2.5 \mathrm{mg} / \mathrm{kg}$ of risperidone was administered. 


\section{DISCUSSION}

The major aim of this study was to show that the atypical APD risperidone will produce in the LI model a pattern of action previously shown by us for clozapine (Shadach $e t$ al, 2000), namely, that it will potentiate LI via effects on conditioning under conditions that do not lead to LI in controls, and disrupt LI via effects on pre-exposure under conditions that lead to LI in controls.

Experiments 5-7 showed that with parameters of preexposure and conditioning that did not produce LI in the vehicle condition (40 pre-exposures and five conditioning trials), risperidone at the $0.25,0.5$, and $1.2 \mathrm{mg} / \mathrm{kg}$ doses led to the emergence of LI when administered in conditioning. This shows that risperidone produces in the LI model the 'typical' LI potentiating action that has been shown for all typical and atypical APDs tested to date (for reviews see Moser et al, 2000; Weiner et al, 2000), and extends previous findings that this potentiating effect is exerted at the conditioning stage (Gray et al, 1997; Joseph et al, 2000; Peters and Joseph, 1993; Shadach et al, 1999, 2000; Weiner et al, 1997). The potentiating effect was not obtained with the highest dose, $2.5 \mathrm{mg} / \mathrm{kg}$; as can be seen in Figure 8, this was because of a reduction in suppression in both the PE and NPE groups produced by this dose. The most reasonable explanation of the latter result is that this dose impaired conditioning irrespective of the animals' preexposure history (Weiner, 2001). Decreased overall suppression that masks drug effects on LI has been reported also with other typical and atypical APDs (Feldon and Weiner, 1991; Moran et al, 1996). However, it should be noted that in Experiment 3, which used two tone-shock pairings, this same dose reduced suppression in both the $\mathrm{PE}$ and NPE groups without eliminating LI. This difference may stem from different batches of rats used or may reflect a genuine interaction between the effects of the drug and the impact of conditioning.

Experiments 1-3 showed that with parameters of preexposure and conditioning that produced LI in the vehicle condition (40 pre-exposures and two conditioning trials), risperidone at all three doses tested disrupted LI when administered in pre-exposure. This extends our previous demonstration of such a pre-exposure-based disruptive effect by clozapine (Shadach et al, 2000). As shown by us previously (Shadach et al, 2000), and in Experiment 4 here, this disruptive effect is not obtained with the typical APD haloperidol. Taken together, these results demonstrate that atypical APDs exert in the LI model a dual pattern of effects, which enables detection of their 'typical' action (conditioning-based LI potentiation under conditions that do not produce LI in controls), as well as a dissociation from typical APDs by their 'atypical' action (pre-exposure-based LI disruption under conditions that produce LI in controls).

In addition, the present results showed that the effects of risperidone administration in both the pre-exposure and conditioning stages were dose-dependent, so that the preexposure-based disruption of LI was manifested at lower but not at higher doses. There is evidence suggesting that the conditioning-based potentiating action is DA-mediated, whereas the pre-exposure-based disruptive action is 5HTmediated: (1) The potentiating effect is obtained with the D2 blocker haloperidol (Joseph et al, 2000; Peters and Joseph,
1993; Weiner et al, 1997) but not with the 5HT2 antagonist ritanserin (Shadach et al, 2000). (2) DA mechanisms are not involved in pre-exposure: neither amphetamine (Weiner et al, 1984, 1988) nor APDs (Shadach et al, 2000; Weiner et al, 1987) affect LI when administered in pre-exposure only. (3) LI tends to be disrupted by reductions in serotonin (Asin $e t$ al, 1980; Cassaday et al, 1993a, b; Lorden et al, 1983; Solomon et al, 1980). (4) all the serotonergic manipulations, including the selective 5HT2A antagonist ritanserin (Shadach et al, 2000), tested to date in the different stages of LI procedure, have been shown to exert their effects at the preexposure stage (Moser et al, 2000).

The present results are consistent with the possibility that the competition between the pre-exposure-based and conditioning-based effects of risperidone reflects a competition between its 5HT2A and D2 antagonistic actions. Since 5HT2A and D2 receptor occupancy predominate at lower and higher doses of risperidone, respectively, low doses can be expected to produce a predominantly serotonergic action, which should be counteracted by its dopaminergic action as the dose increases, and this is the pattern of effects we obtained here. With 40 pre-exposures and two conditioning trials, both the 0.25 and $0.5 \mathrm{mg} / \mathrm{kg}$ doses disrupted LI when given in pre-exposure, as well as when given in both the preexposure and conditioning stages, indicating that the serotonergic action at these doses overrode the dopaminergic action. Indeed, an identical pattern of action was shown by us previously with the selective $5 \mathrm{HT} 2 \mathrm{~A}$ antagonist ritanserin (Shadach et al, 2000). At the $2.5 \mathrm{mg} / \mathrm{kg}$ dose, risperidone abolished LI when given in pre-exposure, but this action was not manifested when the drug was administered in both stages, suggesting that at this higher dose, the action of risperidone in conditioning counteracted its disruptive effect in pre-exposure. We obtained a similar dose-dependent pattern of results with clozapine. At $5 \mathrm{mg} / \mathrm{kg}$ this drug disrupted LI when given in pre-exposure, but spared LI when given in both stages (Shadach et al, 2000), while at the $2.5 \mathrm{mg} / \mathrm{kg}$ dose, the drug disrupted LI when given in preexposure and in both stages (unpublished observations).

With 40 pre-exposures and five conditioning trials, risperidone at the $0.25 \mathrm{mg} / \mathrm{kg}$ dose potentiated LI when administered in conditioning only, but failed to yield potentiation when administered in both stages, indicating that the conditioning-based DA action was weakened by the pre-exposure-based 5HT action. At the higher doses of 0.5 and $1.2 \mathrm{mg} / \mathrm{kg}$, risperidone was able to potentiate LI when administered in conditioning as well as when administered in both stages, suggesting that at these doses risperidone acted like a D2 antagonist. Again, we previously obtained a similar pattern with clozapine; while this drug potentiated LI at 5 and $10 \mathrm{mg} / \mathrm{kg}$, it was unable to do so at $2.5 \mathrm{mg} / \mathrm{kg}$ (Shadach et al, 1999).

Competition between a 5HT2A-mediated disruptive effect and a D2-mediated potentiating effect has been suggested to explain the failure of clozapine to potentiate LI or to do so within a certain dose range only (Dunn et al, 1993; Moran et al, 1996; Trimble et al, 1998). Our results with clozapine (Shadach et al, 2000) as well as those here with risperidone support this suggestion, and further indicate that: (1) the competing actions of atypical APDs are exerted at different stages of the LI procedure, and can therefore be manifested only if the drugs are administered in both stages; (2) 
depending on the parametric conditions and doses, the serotonergic component should be able to override the dopaminergic component, or vice versa, leading to potentiated, intact, or disrupted LI.

Further studies are needed to provide direct evidence that the LI disruptive effects of atypical APDs are due to their serotonergic antagonism, and to determine how the effects of different atypical APDs are influenced by the balance between their D2 and 5HT2 antagonistic actions. However, our results do show that with increasing doses, risperidone becomes more like a typical APD, consistent with clinical data (Meltzer et al, 1989; Meltzer and Nash, 1991).

Whatever the mechanism of the LI-disrupting action, the present results provide further evidence that the LI model has the capacity to discriminate between typical and atypical APDs, so that: (1) both classes of drugs potentiate LI via their action at the conditioning stage under conditions that do not lead to LI in controls; and (2) atypical but not typical APDs disrupt LI via action at the pre-exposure stage under conditions that lead to LI in controls. If confirmed with additional atypical compounds, the LI model would offer two important advantages in comparison to other behavioral models that have been shown to discriminate between typical and atypical APDs, notably, prepulse inhibition (eg Bakshi and Geyer, 1995; Swerdlow et al, 1996), social isolation (Sams-Dodd, 1997), and the forced swim test (Noda et al, 1995). First, these models achieve the discrimination by demonstrating effectiveness of atypical $v s$ ineffectiveness of typical APDs, so that the discrimination entails, rather paradoxically, loss of specificity for APDs (Weiner et al, 2000). In the LI model, typical and atypical APDs are both effective but exert distinct patterns of action; thus, LI is the only model that can discriminate between the two classes of drugs without losing specificity for APDs. Second, the existing models require previous administration of a propsychotic drug (PCP or MK-801) for demonstrating the dissociation and therefore are likely to reveal only antipsychotic action, which is mediated via neurotransmitter systems affected by the challenge drug. The LI model does not depend on propsychotic drug administration for the manifestation of both the typical and the atypical actions of APDs, but detects them with parametric manipulations of the LI procedure. This implies that LI involves neural and cognitive processes, which are directly and differentially modifiable by typical and atypical APDs.

In this context, it is important to point out that although our results might be taken to imply that pre-exposure-based LI disruption should become a critical behavioral index of the antipsychotic action of atypical APDs, this is by no means the case, because our modeling stresses a pattern of drug effects rather than their isolated actions. Thus, in order to qualify as an atypical APD, a compound must disrupt LI via effects on pre-exposure and potentiate LI via effects on conditioning. Indeed, while APD-induced potentiation of LI is specific and selective for APDs, this is not the case with APD-induced disruption of LI because additional compounds (eg ritanserin or chlordiazepoxide; see Moser et al, 2000) have been shown to disrupt LI via effects on preexposure. An intriguing possibility is that any compound, which potentiates LI via effects on conditioning (via D2 blockade) and disrupts LI via effects on pre-exposure (via any mechanism), may possess properties of an atypical APD.

Finally, the distinct effects of typical and atypical APDs in LI have important implications for the LI model of schizophrenia and APD action. It is commonly asserted that both typical and atypical APDs are effective against positive symptoms whereas atypical APDs have higher efficacy for negative symptoms/treatment-resistant schizophrenia, and that therefore an animal model that is sensitive to both classes of APDs may have predictive validity for the former condition whereas a model that is sensitive to atypical but not typical APDs may have predictive validity for the latter condition(s) (Arnt and Skarsfeldt, 1998; Brunello et al, 1995; Kinon and Lieberman, 1996). Viewed in this light, APD-induced LI potentiation may have predictive validity for the treatment of positive symptoms whereas APD-induced LI disruption may have predictive validity for the treatment of negative symptoms/treatmentresistant schizophrenia.

It is apparent however that while the capacity of APDs to potentiate LI, that is, to normalize disrupted LI, is congruent with a beneficial or therapeutic action of APDs, because disrupted LI is considered to model a cognitive impairment in schizophrenia, the capacity of APDs to disrupt normal LI is at first sight incongruent with therapeutic action. With regard to the latter, we (Weiner, 2000, in press; Weiner et al, 2000) have recently drawn attention to the fact that following certain pharmacological and lesion manipulations LI exhibits an opposite pole of abnormality, namely, persists under conditions that disrupt LI in intact rats, and suggested that persistent LI may model attentional perseveration, or impaired attentional set shifting, associated with negative symptoms (Weiner, in press; Weiner et al, 2000). We further suggested that whereas the capacity of APDs to potentiate LI should be 'therapeutic' for disrupted LI, the capacity of atypical APDs to disrupt LI should be 'therapeutic' for abnormally persistent LI. We have recently shown that LI persistence induced by nucleus accumbens core lesion and systemic administration of the NMDA antagonist MK-801 is reversed by clozapine but not by haloperidol administered in preexposure (Gaisler and Weiner, 2001; Zuckerman et al, 2001). In light of the above, we suggest that the characterization of the APD action in the LI model of schizophrenia can be reformulated as follows: both typical and atypical APDs normalize disrupted LI (which models positive symptoms) whereas only atypical APDs normalize persistent LI (which models negative symptoms).

In sum, the present findings provide a foundation for an animal model that is capable of revealing a unique behavioral profile of atypical APDs and differentiating them from typical APDs without the use of propsychotic drugs, and thus provide a useful tool for screening novel agents with atypical antipsychotic profile with relevance to the treatment of negative symptoms/treatment-resistant schizophrenia.

\section{REFERENCES}

Arnt J, Skarsfeldt T (1998). Do novel antipsychotics have similar pharmacological characteristics? A review of the evidence. Neuropsychopharmacology 18: 63-101. 
Asin KE, Wirtshafter D, Kent EW (1980). The effects of electrolytic median raphe lesions on two measures of latent inhibition. Behav Neur Biol 28: 408-417.

Bakshi VP, Geyer MA (1995). Antagonism of phencyclidine-induced deficits in pre-pulse inhibition by the putative atypical antipsychotic olanzapine. Psychopharmacology 122: 198-201.

Baruch I, Hemsley D, Gray JA (1988a). Differential performance of acute and chronic schizophrenics in a latent inhibition task. $J$ Nerv Ment Dis 176: 598-606.

Baruch I, Hemsley DR, Gray JA (1988b). Latent inhibition and 'psychotic proneness' in normal subjects. Perspect Indiv Differ 9: 777-783.

Braunstein-Bercovitz H, Lubow RE (1998). Are high schizotypal normal participants distractible or limited in attentional resources? A study of latent inhibition as a function of masking task load and schizotypy. J Abnorm Psychol 107: 659-670.

Brunello N, Masotto C, Steardo L, Markstein R, Racagni G (1995). New insights into the biology of schizophrenia through the mechanism of action of clozapine. Neuropsychopharmacology 13: 177-213.

Cassaday HF, Hodges H, Gray JA (1993a). The effects of ritanserin, RU 24969 and 8-OH-DPAT on latent inhibition in the rat Psychopharmacology 7: 63-71.

Cassaday HJ, Mitchell SN, Williams JH, Gray JA (1993b). 5,7Dihydroxytryptamine lesions in the fornix-fimbria attenuate latent inhibition. Behav Neurol Biol 59: 194-207.

Christison GW, Atwater GE, Dunn LA, Kilts CD (1988). Haloperidol enhancement of latent inhibition: relation to therapeutic action? Biol Psychiatry 23: 746-749.

Coutureau E, Gosselin O, Di Scala G (2000). Restoration of latent inhibition by olanzapine but not haloperidol in entorhinal cortex-lesioned rats. Psychopharmacology 150: 226-232.

De la Casa LG, Ruiz G, Lubow RE (1993). Latent inhibition and recall/recognition of irrelevant stimuli as a function of preexposure duration in high and low psychotic-prone normals. $\mathrm{Br}$ J Psychol 84: 119-132.

Della Casa V, Hofer I, Weiner I, Feldon J (1999). Effects of smoking status and schizotypy on latent inhibition.J Psychopharmacol 13 45-57.

Dunn LA, Atwater GE, Kilts CD (1993). Effects of antipsychotic drugs on latent inhibition: sensitivity and specificity of an animal behavioral model of clinical drug action. Psychopharmacology 112: 315-323.

Feldon J, Weiner I (1991). The latent inhibition model of schizophrenic attention disorder. Haloperidol and sulpiride enhance rats' ability to ignore irrelevant stimuli. Biol Psychiatry 29: 635-646.

Gaisler I, Weiner I (2001). The effect of MK-801 on latent inhibition are selectively reversed by clozapine but not haloperidol. Biol Psychiatry 2: 175.

Gosselin G, Oberling P, Di Scala G (1996). Antagonism of amphetamine-induced disruption of latent inhibition by the atypical antipsychotic olanzapine in rats. Behav Pharmacol 7: $820-826$.

Gray NS, Hemsley DR, Gray JA (1992a). Abolition of latent inhibition in acute, but not chronic, schizophrenics. Neurol Psychiatr Brain Res 1: 83-89.

Gray JA, Moran PM, Grigoryan G, Peters SL, Young AMJ, Joseph MH (1997). Latent inhibition: the nucleus accumbens connection revisited. Behav Brain Res 88: 27-34.

Gray NS, Pickering AD, Hemsley DR, Dawling S, Gray, JA (1992b). Abolition of latent inhibition by a single low dose of amphetamine in man. Psychopharmacology 107: 425-430.

Gray NS, Pilowsky LS, Gray JA, Kerwin RW (1995). Latent inhibition in drug naive schizophrenics: relationship to duration of illness and dopamine D2 binding using SPET. Schizophr Res 17: 95-107.
Ichikawa J, Meltzer HY (1999). Relationship between dopaminergic and serotonergic neuronal activity in the frontal cortex and the action of typical and atypical antipsychotic drugs. Eur Arch Psychiatry Clin Neurosci 249: 90-8.

Ichikawa J, Meltzer HY (2000). The effect of serotonin(1A) receptor agonism on antipsychotic drug-induced dopamine release in rat striatum and nucleus accumbens. Brain Res 858: 252-263.

Joseph MH, Peters SL, Moran PM, Grigoryan GA, Young AM, Gray JA (2000). Modulation of latent inhibition in the rat by altered dopamine transmission in the nucleus accumbens at the time of conditioning. Neuroscience 101: 921-930.

Killcross AS, Dickinson A, Robbins TW (1994a). Amphetamineinduced disruptions of latent inhibition are reinforcer mediated: implications for animal models of schizophrenic attentional dysfunction. Psychopharmacology 115: 185-195.

Killcross AS, Dickinson A, Robbins TW (1994b). Effects of the neuroleptic alpha-flupenthixol on latent inhibition in aversively - and appetitively - motivated paradigms: evidence for dopamine-reinforcer interactions. Psychopharmacology 115: 196-205.

Kinon BJ, Lieberman JA (1996). Mechanisms of action of atypical antipsychotic drugs: a critical analysis. Psychopharmacology 124: $2-34$.

Leysen JE, Janssen PMF, Schotte A, Luyten WHML, Megens AAHP (1993). Interaction of antipsychotic drugs with neurotransmitter receptor sites in vitro and in vivo in relation to pharmacological and clinical effects - role of 5HT(2) receptors. Psychopharmacology 112: S40-S54.

Lorden JF, Rickert EJ, Berry DW (1983). Forebrain monoamines and associative learning: I. Latent inhibition and conditioned inhibition. Behav Brain Res 9: 181-199.

Meltzer HY, Matsubara S, Lee JC (1989). Classification of typical and atypical antipsychotic drugs on the basis of dopamine D-1, D-2 and serotonin2 pK values. J Pharmacol Exp Ther 251: 238246.

Meltzer HY, Nash JF (1991). Effects of antipsychotic drugs on serotonin receptors. Pharmacol Rev 43: 587-604.

Moran PM, Fischer TR, Hitchcock JM, Moser PC (1996). Effects of clozapine on latent inhibition in the rat. Behav Pharmacol 7: 4248.

Moser PC, Hitchcock JM, Lister S, Moran PM (2000). The pharmacology of latent inhibition as an animal model of schizophrenia. Brain Res Rev 33: 275-307.

Noda Y, Yamada K, Furukawa H, Nabeshima T (1995). Enhancement of immobility in a forced swimming test by subacute or repeated treatment with phencyclidine: a new model of schizophrenia. Br J Pharmacol 116: 2531-7.

Peters SL, Joseph MH (1993). Haloperidol potentiation of latent inhibition in rats: evidence for a critical role at conditioning rather than pre-exposure. Behav Pharmacol 4: 183-186.

Rascle C, Mazas O, Vaiva G, Tournant M, Raybois O, Goudemand $\mathrm{M}$ et al (2001). Clinical features of latent inhibition in schizophrenia. Schizophr Res 51: 149-161.

Sams-Dodd F (1997). Effect of novel antipsychotic drugs on phencyclidine-induced stereotyped behaviour and social isolation in the rat social interaction test. Behav Pharmacol 8: 196215.

Schotte A, Janssen PFM, Gommeren W, Luyten WHML, Van Gompel P, Lesage AS et al (1996). Risperidone compared with new and reference antipsychotic drugs: in vitro and in vivo receptor binding. Psychopharmacology 124: 57-73.

Schotte A, Janssen PF, Megens AA, Leysen JE (1993). Occupancy of central neurotransmitter receptors by risperidone, clozapine and haloperidol, measured ex vivo by quantitative autoradiography. Brain Res 631: 191-202.

Shadach E, Feldon J, Weiner I (1999). Clozapine-induced potentiation of latent inhibition is due to its action in the 
conditioning stage: implications for the mechanism of action of antipsychotic drugs. Int J Neuropsychopharmacol 2: 283-291.

Shadach E, Gaisler I, Schiller D, Weiner I (2000). The latent inhibition model dissociates between clozapine, haloperidol, and ritanserin. Neuropsychopharmacology 23: 151-161.

Solomon P, Nichols GL, Kiernan JMI, Kamer RS, Kaplan LJ (1980). Differential effects of lesions in medial and dorsal raphe of the rat: latent inhibition and septo-hippocampal serotonin levels. $J$ Comp Physiol Psychol 94: 145-154.

Swerdlow NR, Braff DL, Hartston H, Perry W, Geyer MA 1996). Latent inhibition in schizophrenia. Schizophr Res 20: 91-103.

Thornton JC, Dawe S, Lee C, Capstick C, Corr PJ, Cotter P et al (1996). Effects of nicotine and amphetamine on latent inhibition in human subjects. Psychopharmacology 127: 164-173.

Trimble KM, Bell R, King DJ (1997). Enhancement of latent inhibition in the rat by the atypical antipsychotic agent remoxipride. Pharmacol Biochem Behav 56: 809-816.

Trimble KM, Bell R, King DJ (1998). Enhancement of latent inhibition in the rat at a high dose of clozapine. J Psychopharmacology 12: 215-219.

Vaitl D, Lipp V (1997). Latent inhibition and autonomic responses: a psycholophysiological approach. Behav Brain Res 88: 85-94.

Warburton EC, Joseph MH, Feldon J, Weiner I, Gray JA (1994). Antagonism of amphetamine-induced disruption of latent inhibition in rats by haloperdiol and ondansetron - implications for a possible antipsychotic action of ondansetron. Psychopharmacology 114: 657-664.

Weiner I (1990). Neural substrates of latent inhibition: the switching model. Psychol Bull 108: 442-461.

Weiner I (2000). The latent inhibition model of schizophrenia. In: Myslobodsky MS, Weiner I (eds). Contemporary Issues in Modeling Psychopathology. Kluwer Academic Publishers: Boston. pp 197-230.

Weiner I (in press). The "two-headed" latent inhibition model of schizophrenia: Modeling positive and negative symptoms and their treatment. Psychopharmacology.

Weiner I (2001). Latent inhibition. In: Crawley JN, Gerfen CR, Rogawski MA, Sibley DR, Skolnick P (eds). Current Protocols in Neuroscience. John Wiley \& Sons: New York.

Weiner I, Feldon J (1987). Facilitation of latent inhibition by haloperidol. Psychopharmacology 91: 248-253.
Weiner I, Feldon J (1997). The switching model of latent inhibition: an update of neural substrates. Behav Brain Res 88: 11-25.

Weiner I, Feldon J, Katz Y (1987). Facilitation of the expression but not the acquisition of latent inhibition by haloperidol in rats. Pharmacol Biochem Behav 26: 241-246.

Weiner I, Gaisler I, Schiller D, Green A, Zuckerman L, Joel D (2000). Screening of antipsychotic drugs in animal models. Drug Dev Res 50: 235-249.

Weiner I, Gal G, Rawlins JN, Feldon J (1996a). Differential involvement of the shell and coresubterritories of the nucleus accumbens in latent inhibition and amphetamine-induced activity. Behav Brain Res 81: 123-33.

Weiner I, Lubow RE, Feldon J (1984). Abolition of the expression but not the acquisition of latent inhibition by chronic amphetamine in rats. Psychopharmacology 83: 194-199.

Weiner I, Lubow RE, Feldon J (1988). Disruption of latent inhibition by acute administration of low doses of amphetamine. Pharmacol Biochem Behav 30: 871-878.

Weiner I, Shadach E, Barkai R, Feldon J (1997). Haloperidol- and clozapine-induced enhancement of latent inhibition with extended conditioning: implications for the mechanism of action of neuroleptic drugs. Neuropsychopharmacology 16: 42-50.

Weiner I, Shadach E, Tarrasch R, Kidron R, Feldon J (1996b). The latent inhibition model of schizophrenia: further validation using the atypical neuroleptic, clozapine. Biol Psychiatry 40: 834-43.

Williams JH, Wellman NA, Geaney DP, Feldon J, Cowen PJ, Rawlins JNP (1997). Haloperidol enhances latent inhibition in visual tasks in healthy people. Psychopharmacology 133: 262-268.

Williams JH, Wellman NA, Geaney DP, Feldon J, Rawlins JN, Cowen PJ (1996). Anti-psychotic drug effects in a model of schizophrenic attentional disorder: a randomised trial of the effects of haloperidol on latent inhibition in healthy people. Biol Psychiatry 40: 1135-1143.

Yee BK, Feldon J, Rawlins JNP (1995). Latent inhibition in rats is abolished by NMDA induced neuronal loss in the retrohippocampal region but this lesion effect can be prevented by systemic haloperidol treatment. Behav Neurosci 109: 227-240.

Zuckerman L, Joel D, Weiner I (2001). Nucleus accumbens core lesion produces persistent latent inhibition which is reversed by clozapine but not haloperidol. Biol Psychiatry 2: S36. 